\title{
An Estimate of the Fold Conformation on Polyethylene Single Crystals by the Method of Surface Halogenation
}

\author{
Tomo-o Oyama, Kohzoh Shiokawa, and Yoshiaki Kawamura* \\ Department of Applied Science, Faculty of Engineering \\ Kyushu University, Hakozaki, Higashi-ku, \\ Fukuoka, 812, Japan.
}

(Received February 17, 1976)

\begin{abstract}
A new experimental method of surface halogenation is proposed for the analysis of the fold conformations of polyethylene single crystals (PE-SC). The preliminary results of such an experiment and a new model proposed for the conformation and structure of the PE-SC surface are reported. This model is based on the fact that folds must have regularity even though they are long and have only a few degrees of flexibility. Folds of PE-SC are made up of two types of conformations. The length and the type of the folds are distributed so that the experimental results are satisfied. The folds of each type form domains and both the types are mutually convertible.
\end{abstract}

KEY WORDS Polyethylene / Single Crystal / Halogenation / Fold Conformation / Surface Structure /

In spite of many investigations, the nature of the fold structure of polyethylene single crystals (PE-SC) - tight or loose, regular or random, etc. -is still an unsolved problem. In particular, the study of the fold conformation is only in an early stage of development. Fold conformation models based on energy calculations have been proposed by McMahon, et al., ${ }^{1}$ Corradini, et al., ${ }^{2}$ and the present authors. ${ }^{3}$ From the analysis of $1300-1400 \mathrm{~cm}^{-1}$ amorphous bands of PE, the presence of GG, GTG, GTTG, and GGTGG conformations in the fold has been discussed by Schonhorn, et al., ${ }^{4} \mathrm{Krimm}$, et al. ${ }^{5}$ and Zerbi, et al. ${ }^{6}$

However, the energy calculations have been restricted only to the adjacent re-entry folds with the same length and conformation, because it is difficult to calculate the interaction between folding chains. ${ }^{3}$ Though the analysis of the amorphous bands is able to show the presence of the conformations with $\mathrm{G}$, it gives no answer to the problem of whether the fold contains $T$ sequences longer than TT or not.

* Present address: Japan Synthetic Rubber Co., 100, Kawajiri, Yokkaichi, 510.
Further, some difficulty arises from the separation of the experimental results into fold and crystal parts. The results frequently include and are averaged over the properties of both the parts. At this point, a chemical modification method is of interest. In this paper, the theoretical background and some preliminary results of conformation analysis by halogenation at the surface of SC are reported and the fold conformation is discussed.

\section{THEORETICAL BACKGROUND}

Random Halogenation of the Surface of PE-SC

Harrison, et al., ${ }^{7}$ studied the bromination of PE-SC. According to them, it is possible to halogenate only the surface of $\mathrm{SC}$, if the reaction is carried out under mild conditions. Saito, et $a l .,{ }^{8}$ analysed the high-resolution NMR spectra of chlorinated PE. They concluded that the distribution of chlorine atoms was statistically random in the region of chlorine content below $40 \mathrm{wt} \%$; chemical units containing geminal dichloride were not observed in this region. From these studies, the random monohalogenation of carbon atoms will be possible 
only at the surface of SC, at least in the early stage of the reaction.

Conformations and $C-X$ Stretching Vibrations of Halogenated Polyethylenes

The halogen atom $(\mathrm{X})$ in halogenated PE (XPE) has two trans sites. Let us represent the atoms at the two trans sites (hydrogen, carbon or halogen atom) by notations $\mathrm{x}$ and $\mathrm{y}$, and the conformations of the two $\mathrm{C}-\mathrm{C}$ bonds on either side of the $C-X$ bond ( $T, G$ or $G^{\prime}$ ) by notations $\mathrm{i}$ and $\mathrm{j}$. Then the conformations around the halogenated secondary carbon atom are represented by the notation $S_{x y}^{i j}$. When the $G^{\prime}$ conformation is excluded, secondary isolated monohalides, vicinal dichlorides, and vicinalvicinal trihalides have four, eight, and ten different conformations, respectively (including GG $^{\prime}$ conformation, the corresponding numbers are six, eleven, and fourteen).

The $\mathrm{C}-\mathrm{X}$ stretching bands of secondary halides are relatively sharp and strong, and appear in the region of $700-500 \mathrm{~cm}^{-1}$, in which $P E$ has no striking bands. The frequencies of these bands are closely related to the conformation $S_{x y}^{i j}$, especially to $x$ and $y$. The assignments of these bands to the conformations have been studied by Shimanouchi, et al., ${ }^{9}$ Shipman, et al., ${ }^{10}$ Bentley, et al., ${ }^{11}$ Iimura, et al., ${ }^{12,13}$ and Gates, et al. ${ }^{14}$ though some uncertainties have remained, especially in bromides and iodides. Therefore, in principle, if all the bands are resolved, conformation analysis can be carried out with no assumptions. For example, in a model compound such as 3-chloropentane, four $\mathrm{C}-\mathrm{X}$ bands are

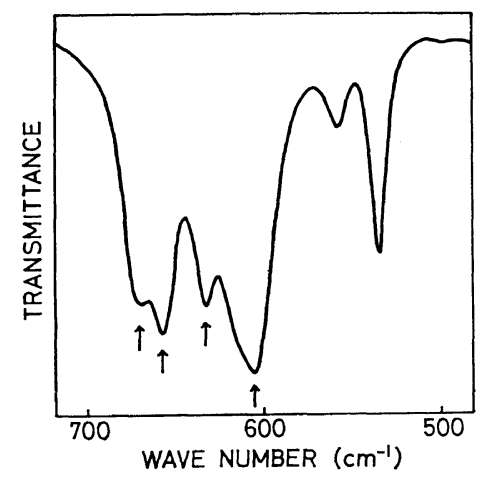

Figure 1. Four $\mathrm{C}-\mathrm{Cl}$ stretching bands of 3-chloropentane.

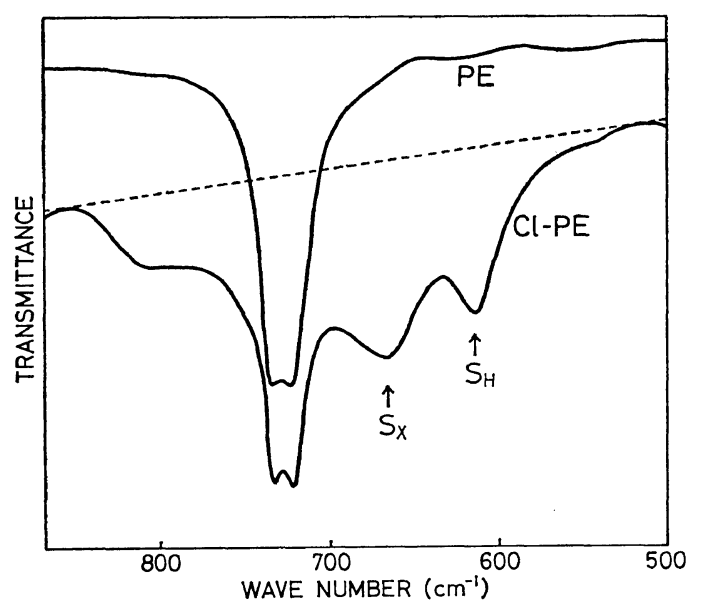

Figure 2. $\mathrm{C}-\mathrm{Cl}$ stretching bands $\left(\mathrm{S}_{\mathrm{H}}\right.$ and $\left.\mathrm{S}_{\mathrm{X}}\right)$ of a chlorinated polyethylene: Sample, $70^{\circ} \mathrm{C}$ crystallized single crystal; chlorine content, $14.3 \%$.

resolved into $610 \mathrm{~cm}^{-1}, 638 \mathrm{~cm}^{-1}, 660 \mathrm{~cm}^{-1}$, and $675 \mathrm{~cm}^{-1}$, as shown by the arrows in Figure 1 . These bands are assigned to $\mathrm{S}_{\mathrm{HH}}^{\mathrm{TT}}, \mathrm{S}_{\mathrm{HH}}^{\mathrm{TG}}, \mathrm{S}_{\mathrm{CH}}^{\mathrm{TG}}$, and $\mathbf{S}_{\mathrm{CH}}^{\mathrm{GG}}$, respectively. Then, from the temperature dependence of the intensities of these bands, the energy differences between various conformations and the distribution of conformations at a given temperature can be estimated.

However, in $\mathrm{Cl}-\mathrm{PE}$, only two bands at 610 $\mathrm{cm}^{-1}$ and $670 \mathrm{~cm}^{-1}$ are observed; these bands are broader than the $\mathrm{C}-\mathrm{X}$ bands of 3-chloropentane, as shown in Figure 2. In comparison with the four bands of 3-chloropentane, therefore, the following assumptions are needed. The $610 \mathrm{~cm}^{-1}$ band is the overlapping band of the $S_{\mathrm{HH}}^{\mathrm{TT}}$ and $S_{\mathrm{HH}}^{\mathrm{TG}}$ bands, namely the $S_{\mathrm{H}}$ band of Shimanouch, et al., ${ }^{9}$ and the $670 \mathrm{~cm}^{-1}$ band is the overlapping band of the $S_{\mathrm{CH}}^{\mathrm{TG}}$ and $S_{\mathrm{CH}}^{\mathrm{GG}}$ bands, namely the $S_{X}$ band of Shimanouchi, et al. With the increase of the vicinal dichloride, the $S_{\mathrm{ClH}}^{\mathrm{TT}}$ and $S_{\mathrm{C} 1 \mathrm{H}}^{\mathrm{TG}}$ bands are overlapped with the $S_{\mathrm{X}}$ band. And it is further assumed that the $S_{\mathrm{C} 1 \mathrm{Cl}}^{\mathrm{TT}}, \mathrm{S}_{\mathrm{C} 1 \mathrm{C}}^{\mathrm{TG}}$, $S_{\mathrm{ClCl}}^{\mathrm{TG}}$, and $\mathbf{S}_{\mathrm{ClC}}^{\mathrm{GT}}$ bands are not included in those two bands.

If the substituted chlorine atoms are randomly distributed, the probabilities of the conformation are given as in Table $\mathrm{I}$, where $X$ is the degree of substitution represented by the number of the chlorine atoms per carbon atom. The intensity ratio of the $\mathrm{S}_{\mathrm{X}}$ and $\mathrm{S}_{\mathrm{H}}$ bands, $r\left(\mathrm{~S}_{\mathrm{X}} / \mathrm{S}_{\mathrm{H}}\right)$, is 
Fold Conformation on Polyethylene Single Crystals

Table I. Probabilities of conformations ${ }^{a}$

\begin{tabular}{|c|c|c|c|}
\hline & $\mathrm{TT}$ & TG & GG \\
\hline $\begin{array}{l}\text { Conformation } \\
\text { Probability of } \\
\text { the substitution }\end{array}$ & 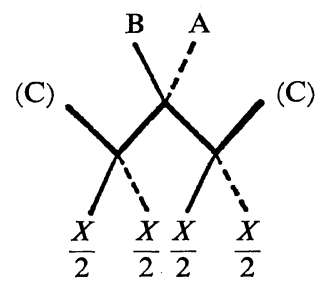 & $\underbrace{}_{\frac{X}{2}}$ & ${ }_{\frac{x}{2}}(\mathrm{C})(\mathrm{C}) \frac{X}{2}$ \\
\hline For halide $\mathrm{A}$ & $\begin{array}{l}\mathbf{S}_{\mathrm{HH}}^{\mathrm{TT}}=\left(1-\frac{X}{2}\right)^{2} \\
\mathbf{S}_{\mathrm{ClH}}^{\mathrm{TT}}=2 \frac{X}{2}\left(1-\frac{X}{2}\right) \\
\mathbf{S}_{\mathrm{ClCl}}^{\mathrm{TT}}=\left(\frac{X}{2}\right)^{2}\end{array}$ & $\begin{array}{l}\mathrm{S}_{\mathrm{HH}}^{\mathrm{TG}}=0 \\
\mathrm{~S}_{\mathrm{CH}}^{\mathrm{TG}}=\left(1-\frac{X}{2}\right) \\
\mathrm{S}_{\mathrm{CC} 1}^{\mathrm{TG}}=\frac{X}{2}\end{array}$ & $\begin{array}{l}\mathbf{S}_{\mathrm{HH}}^{\mathrm{GG}}=0 \\
\mathbf{S}_{\mathrm{CH}}^{\mathrm{GG}}=\left(1-\frac{X}{2}\right) \\
\mathbf{S}_{\mathrm{CCl} 1}^{G G}=\frac{X}{2}\end{array}$ \\
\hline For halide B & the same as the above & $\begin{aligned} \mathrm{S}_{\mathrm{HH}}^{\mathrm{TG}} & =\left(1-\frac{X}{2}\right)^{2} \\
\mathrm{~S}_{\mathrm{C} 1 \mathrm{H}}^{\mathrm{TG}} & =2 \frac{X}{2}\left(1-\frac{X}{2}\right) \\
\mathrm{S}_{\mathrm{C} 1 \mathrm{Cl} 1}^{\mathrm{TG}} & =\left(\frac{X}{2}\right)^{2}\end{aligned}$ & the same as the above \\
\hline
\end{tabular}

a $X$, the degree of substitution (the number of the chlorine atoms per carbon atom).

given by the following equation:

$$
\begin{aligned}
r\left(\frac{\mathrm{S}_{\mathrm{X}}}{\mathrm{S}_{\mathrm{H}}}\right)= & \frac{\kappa_{\mathrm{CH}}^{\mathrm{TG}}\left(n_{\mathrm{TG}} / 2\right)+\kappa_{\mathrm{CH}}^{\mathrm{GG}} n_{\mathrm{GG}}}{\kappa_{\mathrm{HH}}^{\mathrm{TT}} n_{\mathrm{TT}}+\kappa_{\mathrm{HH}}^{\mathrm{TG}}\left(n_{\mathrm{TG}} / 2\right)} \frac{1}{1-X / 2} \\
& +\frac{\kappa_{\mathrm{ClH}}^{\mathrm{TT}} n_{\mathrm{TT}}+\kappa_{\mathrm{ClH}}^{\mathrm{TG}}\left(n_{\mathrm{TG}} / 2\right)}{\kappa_{\mathrm{HH}}^{\mathrm{TT}} n_{\mathrm{TT}}+\kappa_{\mathrm{HH}}^{\mathrm{TG}}\left(n_{\mathrm{TG}} / 2\right)} \frac{2}{1-X / 2}
\end{aligned}
$$

where $\kappa_{x y}^{i j}$ is the absorption coefficient of the $\mathrm{S}_{\mathrm{xy}}^{\mathrm{ij}}$ band and $n_{\mathrm{ij}}$ is the mole fraction of the $\mathrm{ij}$ conformation $\left(n_{\mathrm{TT}}+n_{\mathrm{TG}}+n_{\mathrm{GG}}=1\right)$. The value of $\kappa_{x y}^{i j}$ depends on xy, but is nearly independent of ij. Really, the ratio $\kappa_{\mathrm{HH}}^{\mathrm{TG}} / \kappa_{\mathrm{HH}}^{\mathrm{Tr}}$ of 2-chlorobutane determined by the temperature dependence of the peak intensities is nearly 0.9. Therefore, the following approximations are used: $\kappa_{\mathrm{HH}}^{T T}=$ $\kappa_{\mathrm{HH}}^{\mathrm{TG}}=\kappa_{\mathrm{HH}}, \quad \kappa_{\mathrm{CH}}^{\mathrm{TG}}=\kappa_{\mathrm{CH}}^{\mathrm{GG}}=\kappa_{\mathrm{CH}}$, and $\kappa_{\mathrm{ClH}}^{\mathrm{TT}}=\kappa_{\mathrm{ClH}}^{\mathrm{TG}}=\kappa_{\mathrm{ClH}}$ Then eq 1 is simplified and becomes

$$
\begin{aligned}
r\left(\frac{\mathrm{S}_{\mathrm{X}}}{\mathrm{S}_{\mathrm{H}}}\right)= & \frac{\kappa_{\mathrm{CH}}}{\kappa_{\mathrm{HH}}} \frac{n_{\mathrm{TG}} / 2+n_{\mathrm{GG}}}{n_{\mathrm{TT}}+n_{\mathrm{TG}} / 2} \frac{1}{1-X / 2} \\
& +\frac{\kappa_{\mathrm{ClH}}}{\kappa_{\mathrm{HH}}} \frac{X}{1-X / 2}
\end{aligned}
$$

In $\mathrm{Br}-\mathrm{PE}$, three bands at $549 \mathrm{~cm}^{-1}, 575 \mathrm{~cm}^{-1}$, and $614 \mathrm{~cm}^{-1}$ are well resolved as $\mathrm{C}-\mathrm{X}$ bands, as shown in Figure 3. From the number of available bands and the separation from the

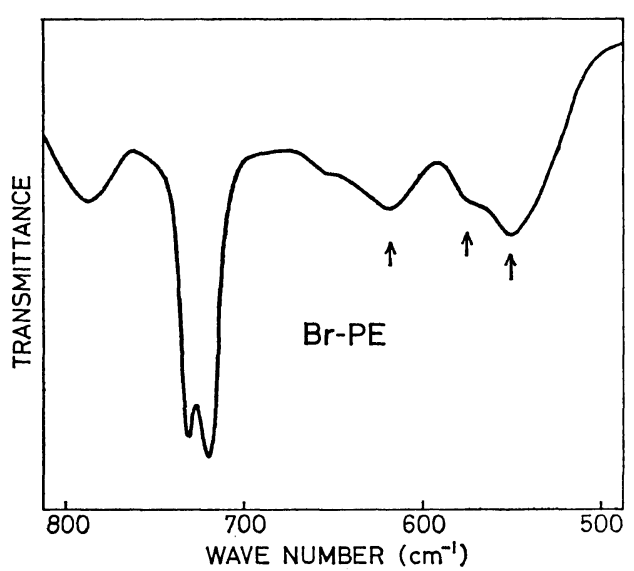

Figure 3. $\mathrm{C}-\mathrm{Br}$ streching bands of a brominated polyethylene: Sample, $70^{\circ} \mathrm{C}$ crystallized single crystal; bromine content, $31.5 \%$.

methylene rocking band at $720 \mathrm{~cm}^{-1}, \mathrm{Br}-\mathrm{PE}$ seems to be more appropriate for the present study than $\mathrm{Cl}-\mathrm{PE}$. However, the assignments of these bands have not yet been established, ${ }^{12}$ unfortunately. This preliminary report is thus restricted to $\mathrm{Cl}-\mathrm{PE}$. 


\section{EXPERIMENTAL}

\section{$P E-S C$}

A linear PE Sholex 6050, with the same characteristics as a Marlex 6050, was used as the sample in this report. The original PE was purified by reprecipitation from xylene-methanol system. Isothermal crystallization was carried out at $70^{\circ} \mathrm{C}\left(70^{\circ} \mathrm{C}-\mathrm{SC}\right)$ and $85^{\circ} \mathrm{C}\left(85^{\circ} \mathrm{C}-\mathrm{SC}\right)$ from $0.6 \%$ xylene solution. PE-SC was obtained by isothermal filtration from the mother liquid and was washed well by hot xylene. The confirmation of $\mathrm{SC}$ was done by $\mathrm{EM}$ observation.

\section{Chlorination of the Surface}

Without drying SC, the xylene was substituted and $\mathrm{SC}$ was suspended into $\mathrm{CCl}_{4}$. Chlorination was done by the bubbling of chlorine gas through the stirring suspension at room temperature under the irradiation of a high-pressure mercury lamp. To protect from oxidation, the reaction was carried out under a nitrogen atmosphere. The degree of chlorination was controlled by the bubbling (and irradiating) time and was determined by elemental analysis.

\section{IR Measurements and Resolution of the Bands}

$\mathrm{Cl}-\mathrm{PE}-\mathrm{SC}$ mats prepared under $550 \mathrm{~atm} / 30 \mathrm{~min}$ at room temperature were used as the specimens for IR measurements. The confirmation that there was no alteration by the press was done by the comparisons of IR spectra and heat of fusion with the $\mathrm{KBr}$ tablet specimen.

The separation of $\mathrm{C}-\mathrm{Cl}$ stretching bands from the $\mathrm{CH}_{2}$ rocking band was made in the following way. The band parameters of the $\mathrm{CH}_{2}$ rocking band were calculated from the IR spectra of PE-SC. In this calculation, the double peak split by the crystal field was treated as a single Lorentzian. The values of the parameters (wave number of the peak, $\nu_{0}$, and half width of the band, $b$ ) were $\nu_{0}=721 \mathrm{~cm}^{-1}$ and $b=8 \mathrm{~cm}^{-1}$. The base line of $\mathrm{Cl}$-PE-SC was drawn as shown in Figure 2. From the total absorption curve, the profile of the $\mathrm{CH}_{2}$ rocking band with the band parameters calculated from PE-SC and with the peak value observed at $\mathrm{Cl}$-PE-SC was subtracted, and then the resolved $S_{X}$ and $S_{H}$ bands were obtained, as will be shown in next section.

\section{DSC Measurements}

DSC measurements were made using a Perkin-
Elmer Model DB-II with a heating rate of $5^{\circ} \mathrm{C} /$ min.

\section{RESULTS}

The results of the DSC measurements are shown in Figure 4. The heat of fusion was nearly unaltered up to the chlorine content of about 20\%. The slight decrease in melting temperature when the chlorine content is increased may be due to the prevention of lamellar thickening or the increase of the entropy of the amorphous phase by the chlorine atoms. These results agree with those of Harrison, et al. ${ }^{7}$ and show that the chlorination took place only at the surface of SC up to the chlorine content of about $20 \%$. The degree of crystallinity calculated from the heat of fusion was $70.2 \%$ for $70^{\circ} \mathrm{C}-\mathrm{SC}$ and $77.8 \%$ for $85^{\circ} \mathrm{C}-\mathrm{SC}$, using $67.0 \mathrm{cal} / \mathrm{g}$ for the heat of fusion of the perfect crystal.

At the early stage of chlorination, the bands due to the vinyl end at $910 \mathrm{~cm}^{-1}, 990 \mathrm{~cm}^{-1}$, and $1650 \mathrm{~cm}^{-1}$ disappeared rapidly. And if there was oxygen present, the strong band of $\mathrm{C}=\mathrm{O}$ at $1720 \mathrm{~cm}^{-1}$ appeared along with the disappearence of the vinyl bands. On the other hand, the band of the $\mathrm{CH}_{3}$ end at $1380 \mathrm{~cm}^{-1}$ was unaltered by the chlorination. This means that the vinyl end is not included in the crystal part.

An example of the band resolution is shown

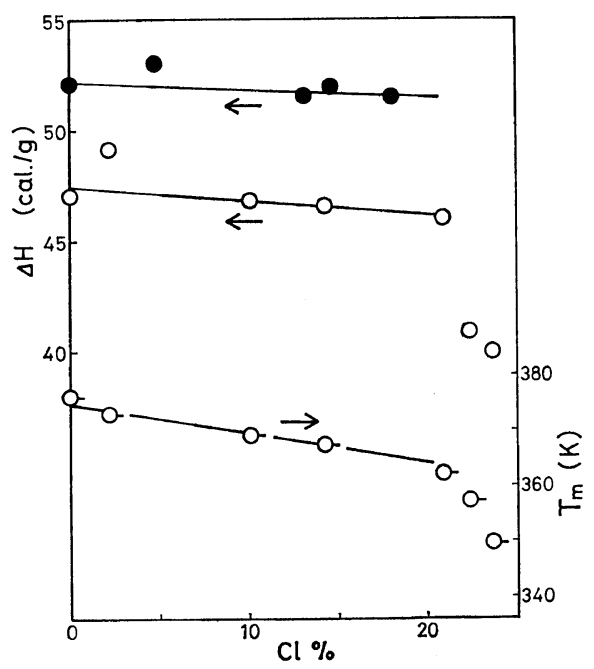

Figure 4. Heat of fusion and melting temperature of chlorinated polyethylenes. 


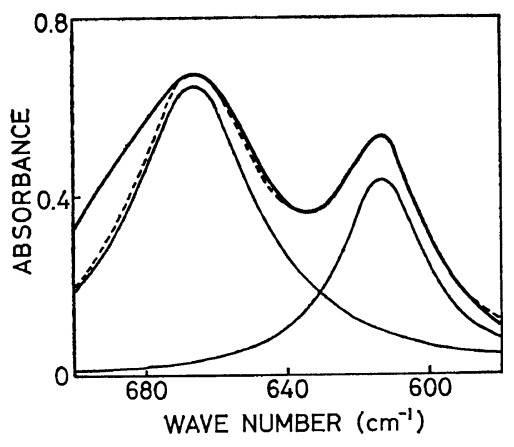

Figure 5. Resolution of $S_{H}$ and $S_{X}$ bands: Sample, $70^{\circ} \mathrm{C}$ crystallized single crystal; chlorine content, $14.3 \%$. The dotted curve represents the sum of the two Lorentzians.

in Figure 5. The values of the Lorentzian parameter, $b$, are $16-24 \mathrm{~cm}^{-1}$ for the $S_{\mathrm{X}}$ band and $10-15 \mathrm{~cm}^{-1}$ for the $S_{\mathrm{H}}$ band. At the higher degree of chlorination, the coincidence between the observed absorption curve and the combined curve of the two Lorentzians becomes less in the higher frequency region, and a small broad band becomes appreciable near $690 \mathrm{~cm}^{-1}$. These are caused by the increase of the $\mathrm{S}_{\mathrm{CH}}$ band of the vicinal dichloride. The frequencies of the $\mathrm{S}_{\mathrm{CH}}$ band of meso- and racemic-2,3-dichlorobutanes have been reported at $695 \mathrm{~cm}^{-1}$ and 703 $\mathrm{cm}^{-1}$, respectively. ${ }^{12}$

The intensity ratio $r\left(\mathbf{S}_{\mathrm{X}} / \mathrm{S}_{\mathrm{H}}\right)$, obtained from the peak heights, is plotted against the chlorine content in Figure 6. In Figure 7, the abscissa is the degree of substitution $X$ per one carbon atom at the surface, which is obtained by using the degree of crystallinity.

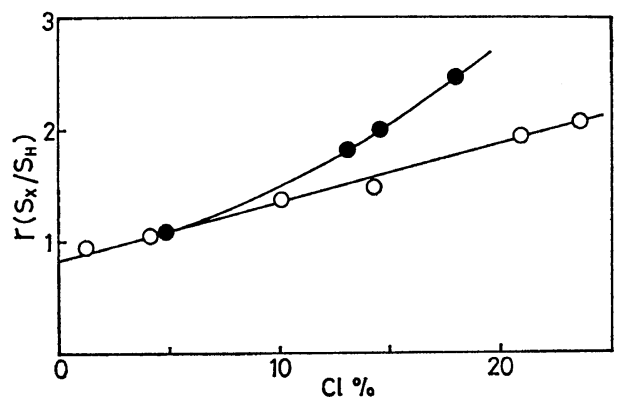

Figure 6. $r\left(\mathrm{~S}_{\mathrm{X}} / \mathrm{S}_{\mathrm{H}}\right)$ as a function of chlorine content (\%): $\bigcirc, 70^{\circ} \mathrm{C}$ crystallized single crystals; $\boldsymbol{O}$, $85^{\circ} \mathrm{C}$ crystallized single crystals.

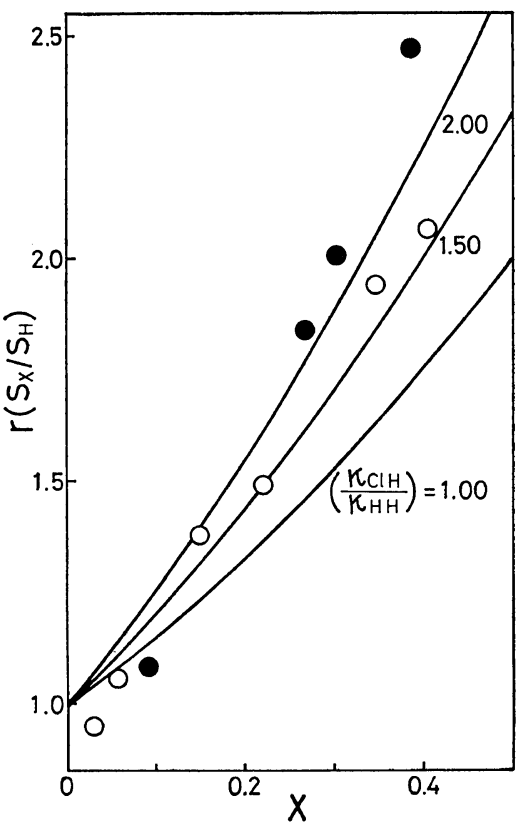

Figure 7. $r\left(\mathrm{~S}_{\mathrm{X}} / \mathrm{S}_{\mathrm{H}}\right)$ as a function of the degree of substitution for the carbon atom on the surface $(X): \quad \bigcirc, 70^{\circ} \mathrm{C}$ crystallized single crystals; $85^{\circ} \mathrm{C}$ crystallized single crystals.

$r\left(\mathrm{~S}_{\mathrm{X}} / \mathrm{S}_{\mathrm{H}}\right)$ is 1.0 at $X=0$ and has the form $\left(\kappa_{\mathrm{CH}} / \kappa_{\mathrm{HH}}\right)\left[\left(n_{\mathrm{TG}} / 2+n_{\mathrm{GG}}\right) /\left(n_{\mathrm{TT}}+n_{\mathrm{TG}} / 2\right)\right]$. The value of $\kappa_{\mathrm{CH}} / \kappa_{\mathrm{HH}}$ for 2-chlorobutane, which is estimated from the temperature dependence of the peakheight ratio, $r\left(\mathrm{~S}_{\mathrm{CH}}^{\mathrm{G}^{\prime}} / \mathrm{S}_{\mathrm{HH}}^{\mathrm{T}}\right)$, is 1.41 . The value for PE-SC may be of the same order. Using the value for 2-chlorobutane, $\left(n_{\mathrm{TG}} / 2+n_{\mathrm{GG}}\right) /\left(n_{\mathrm{TT}}+n_{\mathrm{TG}} /\right.$ 2) becomes nearly 0.7. This means $n_{\mathrm{TT}}>n_{\mathrm{GG}}$ on the surface.

The value of $\kappa_{\mathrm{ClH}} / \kappa_{\mathrm{HH}}$ is unknown at this stage. The $r\left(\mathbf{S}_{\mathrm{X}} / \mathrm{S}_{\mathrm{H}}\right)$ curves calculated by assuming $\kappa_{\mathrm{ClH}} / \kappa_{\mathrm{HH}}$ to be $1.0,1.5$, and 2.0 are shown in Figure 7. The curves with the value in the range of 1.5-2.0 agree with the experimental results. Therefore, such values may be reasonable.

The temperature dependence of $r\left(\mathbf{S}_{\mathrm{X}} / \mathbf{S}_{\mathrm{H}}\right)$ was not obtained for $85^{\circ} \mathrm{C}-\mathrm{SC}$, but was observed reversibly for $70^{\circ} \mathrm{C}-\mathrm{SC}$; a typical example of this is shown in Figure 8. The apparent energy difference between $S_{X}$ and $S_{H}$ for the latter was $640 \mathrm{cal} / \mathrm{mol}$ for the $4.1 \%$ chlorine content sample and $300-350 \mathrm{cal} / \mathrm{mol}$ for the $10.1 . \%$ and the 20.9-\% chlorine content samples. This means that 


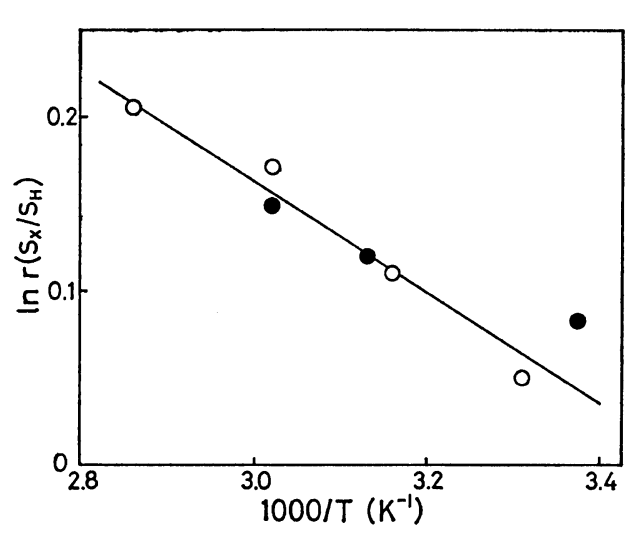

Figure 8. Temperature dependence of $r\left(\mathrm{~S}_{\mathrm{X}} / \mathrm{S}_{\mathrm{H}}\right)$ : Sample, $70^{\circ} \mathrm{C}$ crystallized single crystal; chlorine content, 4.1\%; $\bigcirc$, heating; $O$, cooling.

the fold of SC crystallized at a lower temperature has more degrees of flexibility. The energy differences of $\mathbf{S}_{\mathrm{CH}}^{\mathrm{G}^{\prime}} / \mathbf{S}_{\mathrm{HH}}^{\mathrm{T}}$ and $\mathbf{S}_{\mathrm{HH}}^{\mathrm{G}} / \mathbf{S}_{\mathrm{HH}}^{\mathrm{T}}$ for 2-chlorobutane were $440 \pm 20 \mathrm{cal} / \mathrm{mol}$ and $540 \pm 20 \mathrm{cal} /$ mol, respectively. The energy difference for SC is of the same order as that for 2-chlorobutane.

\section{DISCUSSION}

The results of Figures 4 and 7 indicate that the assumptions described in the THEORETICAL BACKGROUND, random halogenation only at the surface of SC, are approximately satisfied. The information on the fold conformation obtained from the experimental results is not quantitative, because the number of available bands is only two and the exact value of the ratio of the absorption coefficients is not known. However, at least it has been shown that if the fold has certain numbers of GG sequences, there are more TT sequences in the fold. Such information about the TT sequences can not be given by the analysis of the amorphous bands, as mentioned in the introduction.

The average number of carbon atoms in a fold of the present samples is estimated to be 20-30 from the values of the crystallinity and of the long spacing of SC. Since the number in the shortest (tight) regular fold is $7,{ }^{3}$ the folds of the present samples are not tight. Further, the experimental result, that the surface is randomly halogenated and $r\left(\mathrm{~S}_{\mathrm{X}} / \mathrm{S}_{\mathrm{H}}\right)$ of $70^{\circ} \mathrm{C}-\mathrm{SC}$ changes with temperature, suggest that the folds have a few degrees of flexibility.

As is well known, measurements of density and heat of fusion of SC usually give the same results (not-tight and movable) as the present ones that have been interpreted by the longirregular fold model. On the other hand, the results of crystallographic, spectroscopic, and morphological observations have been interpreted by the tight-regular fold model. In order to resolve the inconsistency between these two models, Hoffman and Davis ${ }^{15}$ proposed a new model with physically adsorbed detachable polymer molecules on a fairly regularly folded surface. However, our experimental results can not be interpreted by their model.

\section{A New Model for the Surface of PE-SC}

We now propose a new model which is able to resolve the above inconsistency. Considering the regular growth of $\mathrm{SC}$ and the restriction on folding area (=surface area of SC), the folds, even if they are long, are not random and must have regularity. Most of the folds may be adjacent re-entry. Further, the conformation of the fold must be determined by considering the packing of the folds on the surface of SC. On the basis of this requirement, the conformation of the shortest fold was determined uniquely without conformational freedom. On the other hand, in the case of the long fold, a few degrees of flexibility are required from the experimental results. In order to interpret this fact, it is necessary to consider folds with more than one type of conformation, which can be packed on the surface and can be mutually converted from one type to another.

As described in a previous paper $^{3}$, the crystal structure of PE can be approximated by the sublattice of a diamond lattice; the fold conformation can also be considered on this diamond lattice. As the result of such considerations, two types of conformations for the (110) long fold which satisfy the conditions of the packing and the mutual conversion were found. The conformations of the type A and B are shown in Figures 9 and 10, respectively, where the suffix of $i$ in type $\mathbf{A}$ and of $j$ in type $\mathbf{B}$ is zero or an arbitrary positive integer. If $i$ or $j$ is zero, both the types are reduced to the conformation of the shortest fold, GTGGTGGG, as described 


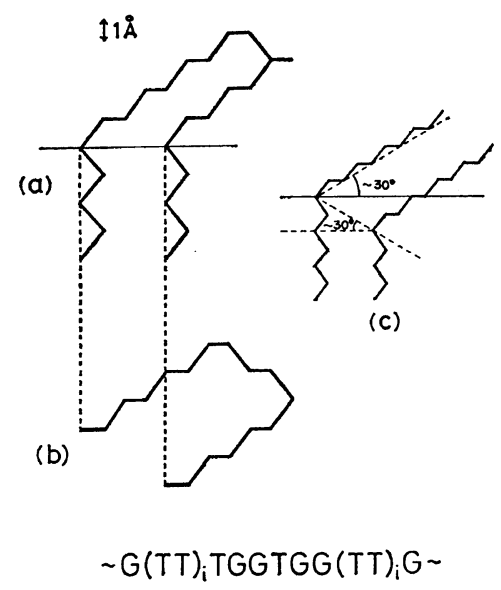

Figure 9. Type A conformation of (110) long folds ( $i$, zero or positive integers), which is able to pack on the crystal surface: (a) (110) projection; (b) (001) projection; (c) relation between adjacent fold planes.

(a)

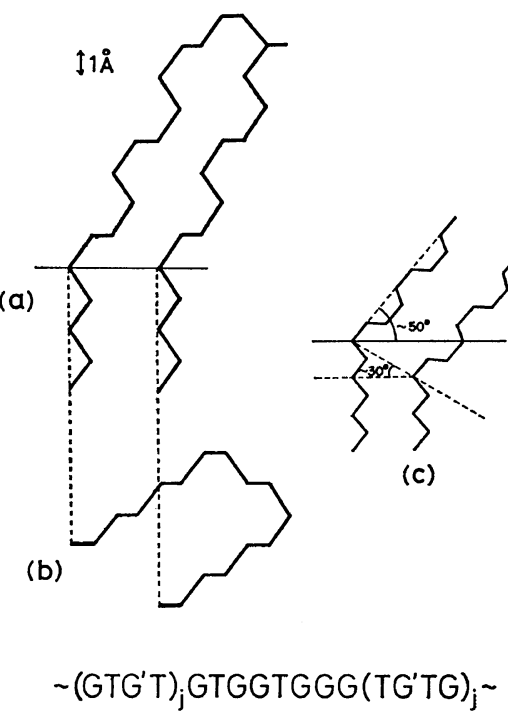

Figure 10. Type B conformation of (110) long folds ( $j$, zero or positive integers), which is able to pack on the crystal surface: (a) (110) projection; (b) (001) projection; (c) relation between adjacent fold planes.

in a previous paper. ${ }^{3}$ GG sequences are located only at the fold-back portion in both types. The conformation of type $A$ is the same as that of ring paraffin molecules in its crystal, while the conformation of the type $B$ is a new one.

A fold with $20-30$ carbon atoms is represented
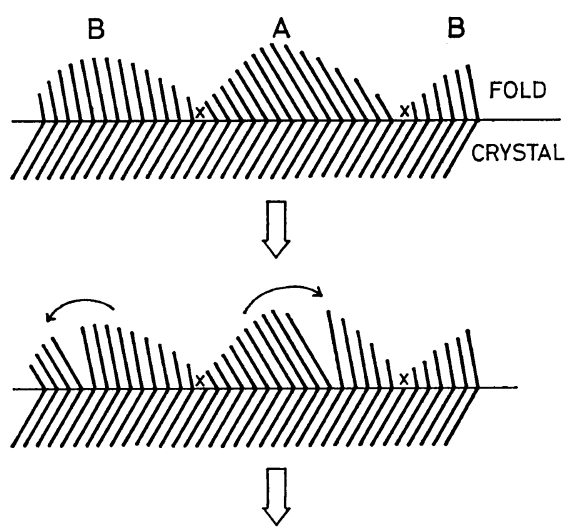

A

B

B

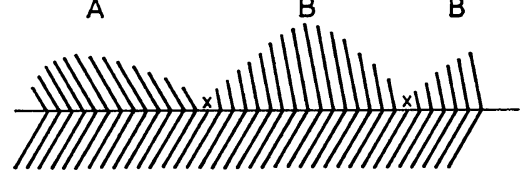

Figure 11. Conversion of fold conformation types (X, the shortest fold).

by type A of $i=4$ with $n_{\mathrm{TT}}=15, n_{\mathrm{GG}}=2$, and $n_{\mathrm{TG}}=8$, or by type B of $j=2$ with $n_{\mathrm{TT}}=0, n_{\mathrm{GG}}=3$, and $n_{\mathrm{TG}}=22$, in which the number of carbon atoms in a fold is 23 . The fold length, however, may not be uniform. The lengths and the types must be distributed so that the experimental results are satisfied.

We have pointed out the importance of the interaction energy between folds (IEF). ${ }^{3}$ IEF between the folds of the different types is larger than that between the folds of the same type, because the degree of packing of the former is less than that of the latter. Therefore, the folds of the same type must form a domain, as is shown in Figure 11. The requirement of the flexibility is fulfilled by the conversion of the fold type, A to B or B to A. An example of the conversion is illustrated in Figure 11.

In our model, as shown in Figures 9, 10, and 11 , the chains in the crystal part are inclined at an angle of $30^{\circ}$ with respect to the normal to the boundary plane between the crystal and the fold parts, due to the steric hindrance between the folds in successive (110) fold planes. This inclination was confirmed recently by the Raman spectroscopic study of PE-SC by Keller, et al. $^{16}$

The experimental results are interpreted well by the model proposed here. However, a few 
problems remain unsolved. The fold part of our model is regular, in other words, crystallike. The energy density of the straight portion of the fold part may be lower than that of the melt, and depends upon the fold type. On the other hand, the energy density' of the fold-back portion is higher than that of the melt. ${ }^{3}$ Therefore, the average energy density of the fold part depends on the distributions of the fold length and fold type. This makes it impossible to calculate the crystallinity from only the fusion data. For this reason, the present discussion is not quantitative, but may be qualitatively correct.

The other problem is the density of PE-SC. In our models for both types of fold, the density is $1.0 \mathrm{~g} / \mathrm{cm}^{3}$ when the length is infinite. For the fold with finite length, the density becomes larger because of the influence of the fold-back portion. Therefore, the experimental density of PE-SC (usually, 0.96-0.98) can not be interpreted by our models. This discrepancy is common to the regular fold models and a study from a new viewpoint will be required for the elucidation of this problem.

Acknowledgement. This work was supported in part by a grant from The Asahi Glass Foundation for the Contribution to Industrial Technology, for which the authors are grateful.

\section{REFERENCES}

1. P. E. McMahon, R. L. McCullough, and A. A. Schlegel, J. Appl. Phys., 38, 4123 (1967).

2. P. Corradini, V. Petraccone and G. Allegra, Macromolecules, 4, 770 (1971).

3. T. Oyama, K. Shiokawa, and T. Ishimaru, $J$. Macromol. Sci.-Phys., B8, 229 (1973).

4. H. Schonhorn and J.P. Luongo, Macromolecules, 2, 366 (1969).

5. S. Krimm and J. Jakeš, ibid., 4, 605 (1971).

6. G. Zerbi, L. Piseri, and F. Cabassi, Mol. Phys., 22, 241 (1971).

7. I. R. Harrison and E. Baer, J. Polym. Sci., Part A-2, 9, 1305 (1971).

8. T. Saito, M. Matsumura, and S. Hayashi, Polym. J., 1, 639 (1970).

9. S. Mizushima, T. Shimanouchi, K. Nakamura, M. Hayashi, and S. Tsuchiya, J. Chem. Phys., 26, 970 (1957).

10. J. J. Shipman, V. L. Folt, and S. Krimm, Spectrochim. Acta, 18, 1603 (1962).

11. F. F. Bentley, N. T. McDevitt, and A. L. Rozek, ibid., 20, 105 (1964).

12. K. Imamura, N. Kawakami, and M. Takeda, Bull. Chem. Soc. Jpn., 42, 2091 (1969).

13. K. Imamura, ibid., 42, 3135 (1969).

14. P. N. Gates, F. F. Mooney and H. A. Willis, Spectrochim. Acta, 23A, 2043 (1967).

15. J. D. Hoffman and G. T. Davis, J. Res. Nat. Bur. Stand., A, 79, 613 (1975).

16. M. J. Folkes, A. Keller, J. Stejny, P. L. Goggin, G. V. Fraser, and P. J. Hendra, Colloid. \& Polym. Sci., 253, 354 (1975). 